\title{
Complex and inconsistent patterns of variation in benthos, micro-algae and sediment over multiple spatial scales
}

\author{
M. G. Chapman*, T. J. Tolhurst, R. J. Murphy, A. J. Underwood \\ Centre for Research on Ecological Impacts of Coastal Cities, Marine Ecology A11, University of Sydney, \\ New South Wales 2006, Australia
}

\begin{abstract}
Because of their close physical relationship, it is often assumed that there are strong functional relationships between sediments and biota. Yet, there have been few studies of the characteristics of sediments over multiple spatial scales, despite evidence that micro-algae and macroand meiofauna vary greatly at $\mathrm{cm}$ to $\mathrm{km}$ scales. This study quantified variability in macrofauna, micro-algae, and physical and biochemical properties of sediments over scales from $50 \mathrm{~cm}$ to $\mathrm{km}$. The benthos was most variable at small scales and, even where there were large mean differences in abundance at large scales, these were small compared to the variation from plot to plot along a shore. Only 1 of 24 analyses showed larger variation at the scale of $\mathrm{km}$ than that found at $50 \mathrm{~cm}$. Some measures of microphytobenthos showed large variation at the scale of $100 \mathrm{~s} \mathrm{~m}$ or more, but other measures of the same flora did not show similar patterns. Concentrations of sand were consistent at different depths and at large scales, but concentrations of mud were more variable within than among shores. Neither sand nor mud correlated significantly with most biochemical properties of sediments. For sediments, variation at the scale of $\mathrm{km}$ was only larger than that of $50 \mathrm{~cm}$ in 13 of 57 analyses. To understand the relative importance of ecological processes in determining distributions and abundances, it is important to get quantitative data on the scales at which organisms or habitats vary. These are the scales at which ecological processes are likely to have large effects because large-scale processes are unlikely to explain variation at much smaller scales. The importance of small-scale variability in sediments and the associated biota is discussed in terms of sampling protocols for understanding ecological processes, or for assessing impact or restoration.
\end{abstract}

KEY WORDS: Intertidal soft sediment $\cdot$ Microphytobenthos $\cdot$ Benthic assemblage $\cdot$ Spatial patterns Components of variation $\cdot$ Scales

Resale or republication not permitted without written consent of the publisher

\section{INTRODUCTION}

Many studies on spatial variation in fauna and microflora in sediments have focussed on differences at large scales, e.g. 100s m to km (Underwood \& Paterson 1993, Hansen \& Kristensen 1997), or between large patches of different habitats (Cummings et al. 1998, Thrush et al. 2006). Studies at small scales may show equally large (or larger) differences in fauna, flora or sediments (Luckenbach 1986, Pinckney \& Sandulli 1990, Schaffner 1990, Morrisey et al. 1992, Underwood \& Paterson 1993, Chapman \& Tolhurst 2007, Tolhurst
\& Chapman 2007). Understanding all scales at which there is large variation is essential for integrating the multiplicity of processes that cause patterns in abundances (Wiens 1989, Levin 1992). Nevertheless, in sediments, small scales are often not incorporated into large-scale studies (Sun et al. 1994, Thrush et al. 1996): relevant data have been pooled, thus losing information about variation (Guarini et al. 1998), or small-scale patterns are not considered interesting.

Many ecological processes affecting organisms directly, or indirectly via their habitat, operate at small $(\mathrm{mm}$ to $<1 \mathrm{~m})$ scales within large patchy habitats. 
Although soft sediments may appear relatively uniform, many processes affect them at local scales. Water movement may change topography (Blanchard et al. 2000), assemblages may alter hydrodynamics (Huettel \& Gust 1992) or sedimentary properties (Andersen et al. 2001), foraging (Van Blaricom 1982) or bioturbating (Branch \& Pringle 1987) animals may disturb sediment in small patches. Thus, biotic and/or abiotic processes can alter important features of habitat at a local scale causing considerable small-scale patchiness. Patterns derived from small-scale studies cannot be extrapolated to represent large-scale patterns without adequate sampling to ensure how representative the samples are of different spatial scales (Grant et al. 1997, Thrush et al. 1997, Migne et al. 2004).

Flora and fauna respond to small-scale patchiness in habitat via recruitment (Levin 1984), growth (Forbes \& Lopez 1989), mortality (Kelaher \& Levinton 2003) or dispersal (Commito et al. 1995). Thus, small-scale variability in abundances of organisms may reflect strong responses to the local habitat, rather than simply being 'noise' (Carroll 2003). In contrast to the large number of studies on spatial patterns of macrofauna (see reviews by Ólafsson et al. 1994, Whitlatch et al. 1998, Defeo \& McLachlan 2005), there have been relatively few comparable studies of multiple properties of the sedimentary habitat across many scales, other than some on distribution of chlorophyll as a measure of micro-algae (e.g. Decho \& Fleeger 1988, Saburova et al. 1995). Thus, Pinckney \& Sandulli (1990) showed considerable small-scale patchiness in meiofauna and chlorophyll, but no correlation in patterns of distribution of the fauna and flora. Similarly, Tolhurst \& Chapman (2007) showed that benthic fauna and properties of sediments not only varied among different mangrove habitats, but within habitats at several scales. The particular species and properties that varied the most differed amongst habitats, and properties of sediments were not strongly correlated with abundances of fauna.

Many techniques can quantify spatial variation, e.g. spatial autocorrelation (Pinckney \& Sandulli 1990), semivariograms (Palmer 1988), indices of aggregation (Saburova et al. 1995), fractal analyses (Palmer 1988), hierarchical analyses of variance (Underwood 1981). Not one method is universally applicable because they quantify patchiness in different ways. Methods that rely on contiguous counts along transects are more labour-intensive than hierarchical sampling which can thus provide data over more scales for the same effort. Analyses of variance not only test for significance of each scale, but measure the magnitude of variation for each scale independently of other scales (Morrisey et al. 1992, Underwood \& Chapman 1996). A partial hierarchical (ladder) design can minimize effort fur- ther (Kendall \& Widdicombe 1999), but is more affected by anomalies in the few sites sampled. The major disadvantage of hierarchical analyses is that the scales must be decided in advance and do not 'emerge' from the data. Nevertheless, for many habitats, reasonable hypotheses about the scales that are likely to be important can be constructed based on previous studies and local knowledge.

Different processes operate at different (and possibly multiple) spatial scales to create or maintain variation in biota and/or habitat. Prior to evaluating the importance of such processes, it is necessary to determine (1) scales at which there is large variability and (2) how common patterns are across space and time. Variation only found in 1 or 2 places may indicate patchy processes, or chance events. When patterns are consistent over many places, it is more realistic to look for general processes. Examining mean values and extracting components of variation, rather than simply relying on significance tests of F-ratios, allows one to measure the extent to which any large-scale pattern, e.g. between shores, is due to general differences between the shores, or to isolated large values on only one of the shores (or different, but by chance, numbers of large values on each shore). The former would imply largescale processes are operating; the latter that smallscale processes are operating in isolated patches, or there is much stochastic variation.

There is, however, little current information about multiple spatial scales of variation, for example from $<1 \mathrm{~m}$ to $\mathrm{km}$, for a suite of sedimentary variables that simultaneously includes physical properties, fauna and flora (but see Pinckney \& Sandulli 1990, Azovsky 2002, Chapman \& Tolhurst 2004, 2007, Tolhurst \& Chapman 2007, Murphy et al. 2008 for some components of sediment). Thus, it is not clear how best to sample to detect processes that operate at different spatial scales, nor to determine which scales show large variability that needs to be understood in order to identify ecological processes influencing sediments.

Although many other species may correlate well with physical properties of sediments (e.g. Cummings et al. 1998), even large engineering species may not show such correlations (e.g. Commito et al. 1995. Analysis of broader taxa is therefore often used to identify spatial patterns because individual species are often very patchy and their counts dominated by many zeros. Dethier \& Schoch (2006) showed strong correlations between patterns of species and families along an estuarine gradient. Similarly, Olsgard et al. (2003) showed that distributions of polychaete species in sediments are well correlated with distributions at the scale of family. The first objective of this experiment was thus to quantify spatial variation of physical, biogeochemical and biotic components of 
intertidal mudflats at scales from $<1 \mathrm{~m}$ to $\mathrm{km}$. These data tested the hypotheses that (1) functionally similar components of the assemblage would show similar patterns of variation across different spatial scales, (2) sedimentary properties that are thought to be functionally related would show similar patterns of variation across multiple spatial scales and (3) the scales in which the sediment, micro-algae and the benthos showed maximal amounts of variation would be relatively consistent across locations.

\section{MATERIALS AND METHODS}

Sampling was done twice in estuaries in Sydney (New South Wales, Australia). Two shores in the narrow Kogarah Bay (KB1 and KB2, separated by $<1 \mathrm{~km}$ of water; Fig. 1) were sampled on 1 and 2 September 2005 (Experiment 1, E1). The large number of measurements precluded sampling both shores on the same day, despite a team of 6 researchers per day. To increase the spatial scale, KB1 and a second shore about $5 \mathrm{~km}$ away (Taren Point TP; Fig. 1) were sampled on 13 and 14 March 2006, respectively (Experiment 2, E2). This also allowed a comparison of the patterns for the same shore between 2 periods, 6 mo apart. Each shore was a relatively narrow (<100 m from low to highshore) intertidal mudflat, bounded at the landward edge by urban development or mangroves. Each was very gently sloping and the sediment was a mix of sand and mud. There were small patches of very sparse seagrass Zostera capricorni or filamentous algae, but no other macrophytes. Sampling was designed to exclude the patches of seagrass and there were no visible differences in the sediments between the start and end of each transect.

On each shore, samples were collected over a $562 \mathrm{~m}$ transect. Plots to be sampled were marked out during a 5 min period by following the line of low tide to ensure similar tidal height for all samples. Along each transect, 6 nested spatial scales were examined: 400, 100, 50, 10 and $2 \mathrm{~m}$, with 2 replicate measures, $50 \mathrm{~cm}$ apart in each plot. Thus, there were 128 samples over $562 \mathrm{~m}$, encompassing nested spatial scales from $50 \mathrm{~cm}$ to $400 \mathrm{~m}$ on each of the 2 shores.

Estimates of photosynthetic pigments. Photosynthetic pigments were used as a surrogate for algal biomass using data collected by 2 methods. Concentrations of chlorophyll (chl) $a$ and $b$ were extracted chemically from two $5.7 \mathrm{~cm}$ diameter cryogenic cores ( 3 mm deep) as described by Chapman \& Tolhurst (2004).

Key pigments were also measured using a field spectrometer (Field Spec Pro; Analytical Spectral Devices; Murphy et al. 2005). Reflectance spectra (350 to
$1050 \mathrm{~nm}$ ) from the sediment surface were recorded using an $8^{\circ}$ fore-optic lens, of area $18.7 \mathrm{~cm}^{2}$. For calibration, a reference spectrum from a $\sim 99 \%$ reflective panel (Spectralon) was acquired immediately prior to each spectrum for calibration. Each spectrum was the average of 40 measurements. Absorption features in each were enhanced by derivative analysis using Savitsky \& Golay's (1964) combined smoothing and differentiation technique. Features are manifested as peaks in derivative reflectance above the zero-baseline. Quantitative analysis of these features is often done using 4th-order derivative spectra (Bidigare et al. 1989), but noise in the spectra increases significantly with increasing orders of differentiation (especially in spectra from mud). Second-order derivative spectra were therefore used.

Four principal regions of absorption, representing 4 groups of pigments were identified: (1) carotenoids (477 to $521 \mathrm{~nm}$ ), (2) chl $C$ and phyco-erythrin (570 to $592 \mathrm{~nm}$ ), (3) chl $a$ and $c$ and phycocyanin (611 to $640 \mathrm{~nm}),(4) \mathrm{chl} a$ and $b$ (661 to $693 \mathrm{~nm})$. The relative amounts of these 4 groups of pigments were estimated by summing all reflectance values above the zero-baseline in each of these specified ranges. All algae contain chl a. Assemblages containing diatoms would show large amounts of chl $c$ and carotenoids, increasing absorption in bands (1) to (3). Green algae contain chl $b$, increasing absorption in band (4) relative to other bands. Cyanobacteria contain phyco-erythrin and/or phycocyanin and would be indicated by relatively large amounts of absorption in bands (2) and/or (3).

Other properties of sediments. Full details for assaying the abiotic characteristics of the sediments are in

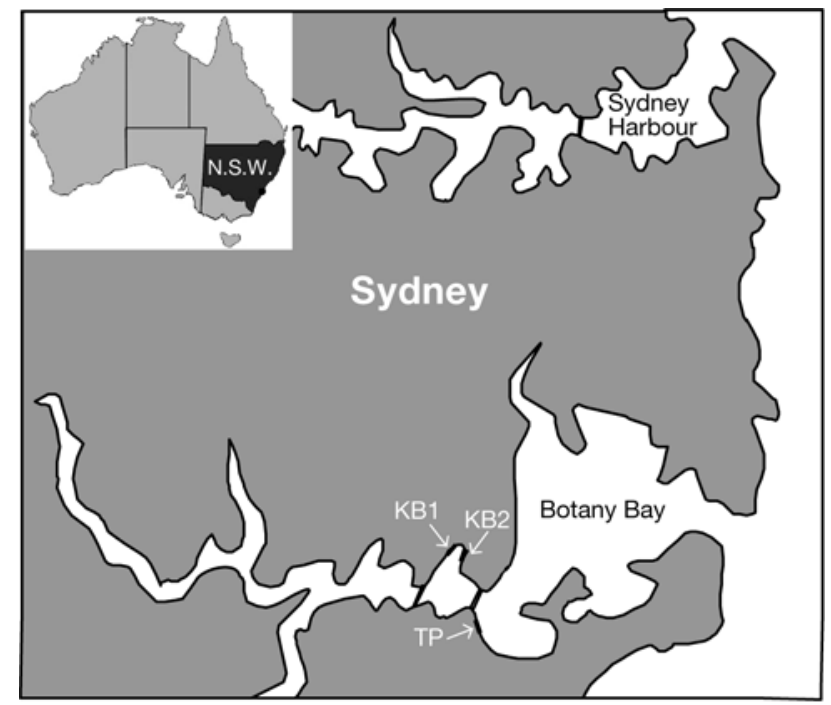

Fig. 1. Study sites KB1 and KB2 on either side of Kogarah Bay $\left(33^{\circ} 59^{\prime} \mathrm{S}, 151^{\circ} 7^{\prime} \mathrm{E}\right)$, Taren Point (TP) is in an adjacent bay $\left(34^{\circ} 1^{\prime} \mathrm{S}, 151^{\circ} 7^{\prime} \mathrm{E}\right)$ 


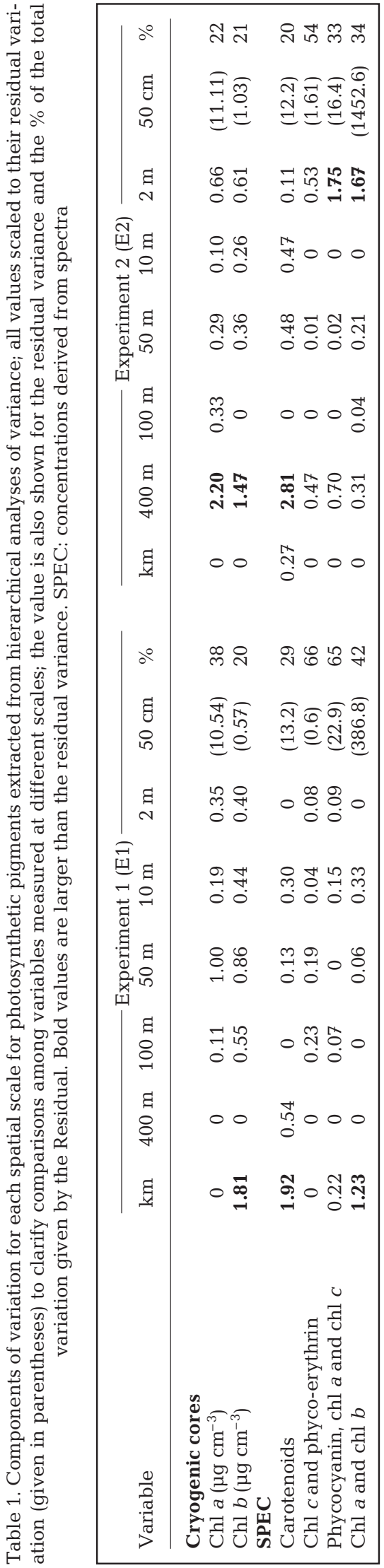

Chapman \& Tolhurst (2004). The threshold and rate of erosion were measured in situ using a Cohesive Strength Meter (Tolhurst et al. 1999). Concentrations of water, mud (grains $<63 \mu \mathrm{m}$ ) and sand (grains $>63 \mu \mathrm{m}$ ) were measured in the top $3 \mathrm{~mm}$ of sediment from the cryogenic cores used to extract chlorophyll. Concentrations of sand and mud were also measured in replicate cores, $2 \mathrm{~cm}$ diameter $\times 2 \mathrm{~cm}$ deep. Biogeochemical measures included concentrations of organic matter (all cores), plus total and colloidal carbohydrate ( $3 \mathrm{~mm}$ cores). All variables were expressed as concentrations (Tolhurst et al. 2005).

Benthos. Benthos was collected in 2 cores of $10 \mathrm{~cm}$ diameter $\times 10 \mathrm{~cm}$ deep in each plot. Sediment was sieved through a $500 \mu \mathrm{m}$ sieve and the retained fauna stained with Bengal Rose and preserved in $7 \%$ formalin in seawater. Taxonomic resolution was mixed, from species/morphospecies (e.g. gastropods) to families (e.g. polychaetes) to broad taxonomic groupings (e.g. oligochaetes, nematodes), depending on the available keys.

Analyses. Each variable was separately analysed using analyses of variance with all factors random and nested in larger spatial scales. The largest scale was $\mathrm{km}(\sim 1 \mathrm{~km}$ in E1 and $\sim 5 \mathrm{~km}$ in E2). On each shore, there were nested scales of 400,100,50, 10 and $2 \mathrm{~m}$, with $\mathrm{n}=2$. Components of variation for each spatial scale were extracted from mean square estimates. Any negative component was set to zero, eliminated from the analysis and components of variation recalculated (Fletcher \& Underwood 2002). These components directly estimate variability at each spatial scale, independent of other spatial scales. Because different variables were measured across different ranges of values, all components were scaled relative to the Mean Square Residual for that analysis to simplify comparisons among analyses. Values $<1$ showed that the additional variance contributed by that particular scale was smaller than the residual variance (i.e. between replicates $50 \mathrm{~cm}$ apart). In contrast, values $>1$ indicated how much more variance was added by that scale relative to the Residual.

\section{RESULTS}

\section{Estimates of photosynthetic pigments}

Twelve components of variance were extracted for each of the 6 spatial scales, i.e. 2 experiments, each with 6 measures of photosynthetic pigments (Table 1). Four measures showed little variation at any scale over and above the Residual (Table 1). These included spectrald (SPEC) estimates of chl $c$ and phyco-erythrin (E1 and E2), chl $a$ and $c$ and phycocyanin (E1), and 
chl a extracted from cores (E1; Table 1). This does not mean that there were no changes along transects, but, instead, a lot of small-scale variation and no general trends with increasing spatial scales (e.g. chl $c$ and phyco-erythrin from E1 in Fig. 2a).

Other variables showed that some scales were consistently important (i.e. component of variation > Residual) within, but not between experiments (bold type in Table 1). In E1, the remaining 3 variables showed large variation between, but not within shores (Table 1). Carotenoids and chl $a$ and $b$ (SPEC) had larger values on KB2 (Fig. 2b) and chl $b$ (cores) had larger measures on KB1 (Fig. 2c). Even though chl a and $b$ showed different patterns of variation for the extracted components of variation, their values were positively correlated at the scale of plots (Fig. 3a). In contrast, chl $b$ and the 2 SPEC measures each identified large between-shore variation, but they were not correlated (Fig. 3b).

In E2, there were no major differences between shores, but 2 smaller spatial scales showed large variation. Chl $a$ and $c$ and phycocyanin, and chl $a$ and $b$ (SPEC) varied at the scale of $2 \mathrm{~m}$ (Table 1),
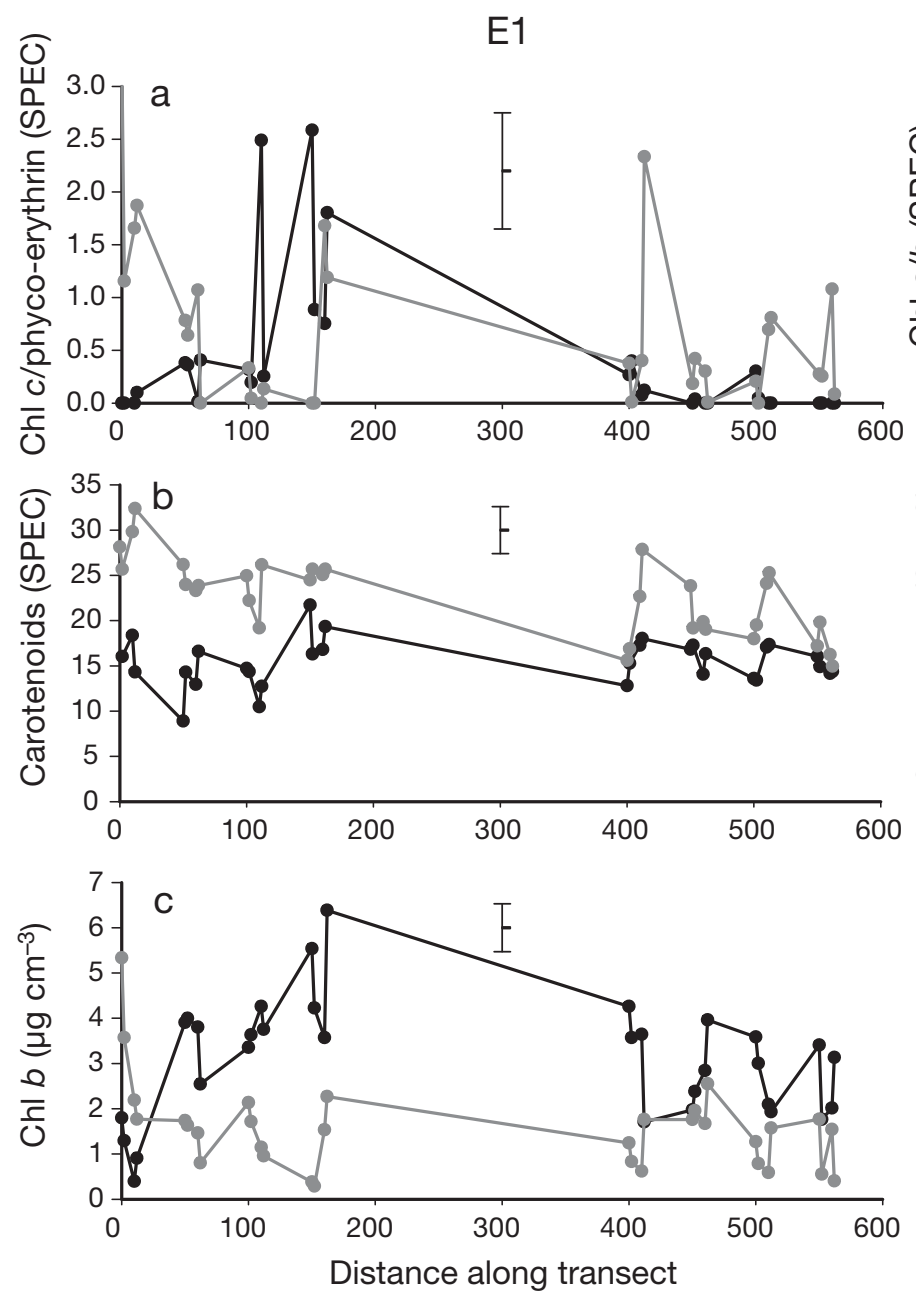

mainly due to occasional 'high spots' along a transect (illustrated for chl $a$ and $b$ in Fig. 2d). Carotenoids (SPEC) and extracted chl $a$ and $b$ (cores) showed large variation at the scale of $400 \mathrm{~m}$ (Table 1) due entirely to a change along only one of the shores (KB1 in Fig. 2e). Despite chl $a$ and $b$ showing similar patterns of variation in this experiment, they were less strongly correlated than in E1 (Fig. 3c). Similarly, although carotenoids showed similar scales of variation to those of the extracted chlorophyll, they were poorly correlated (Fig. 3d). Carotenoids were well correlated with SPEC measures of chl $a$ and $b$ (Fig. 3e), but, in E2, they showed different patterns for the components of variation.

\section{Other components of sediments}

There were 21 analyses (E1:10, E2:11; Table 2). These measures were more variable than were the pigments, both between experiments for the same measure and among measures in the same experiment. Most variation was at the scale of $50 \mathrm{~cm}$, with the
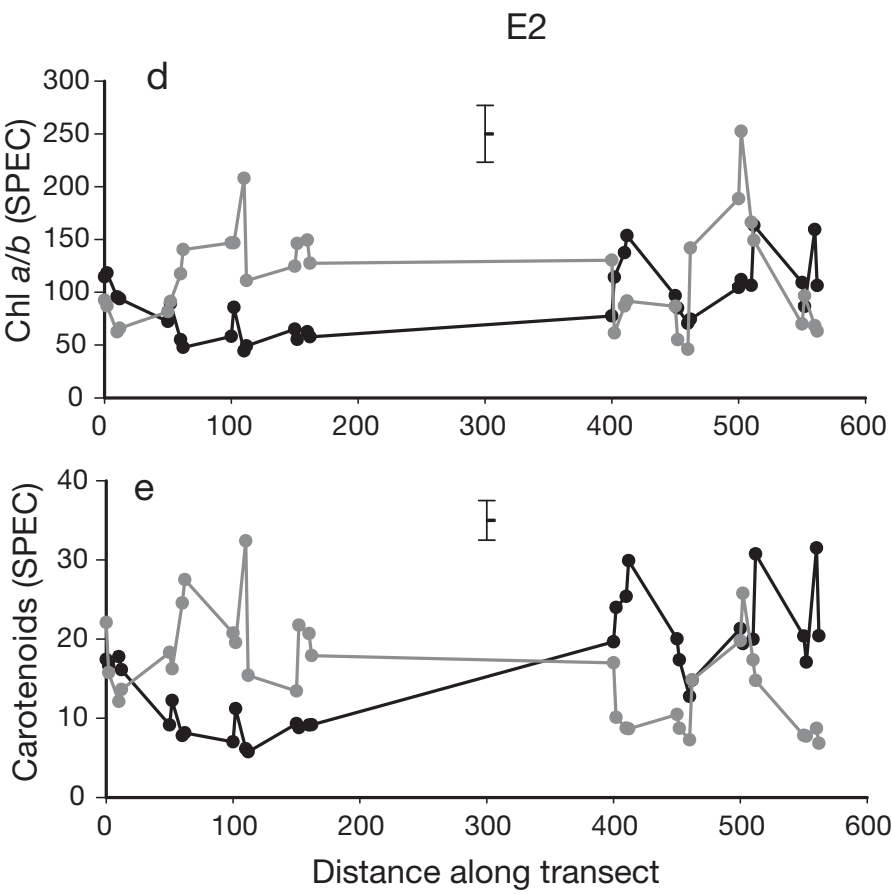

Fig. 2. Means $(\mathrm{n}=2)$ in each of 32 plots along a $562 \mathrm{~m}$ transect on each of 2 shores for (a) chl $C$ and phyco-erythrin, E1; (b) carotenoids (SPEC; E1); (c) chl $b$ (cryogenic cores; E1); (d) chl $a$ and $b$ (SPEC; E2); (e) carotenoids (SPEC; E2); error bar is the mean SE for all plots. SPEC: concentrations derived from spectra; black $=$ KB1, gray $=$ KB2 $(E 1)$ or TP (E2) (see Fig. 1 for details of sites) 
larger scales contributing more variation to the total than did the Residual in only 11 of the analyses. These measures included amounts of water, organic matter, mud, colloidal carbohydrate and rate or threshold of erosion in either 1 or both experiments (Table 2). This was not due to lack of differences among plots, but to apparent chaotic variability from plot to plot (see concentrations of water in E2 in Fig. 4a). The large SE in this figure indicates the large amount of variability between replicates within plots. Also, in contrast to the

\section{E1}
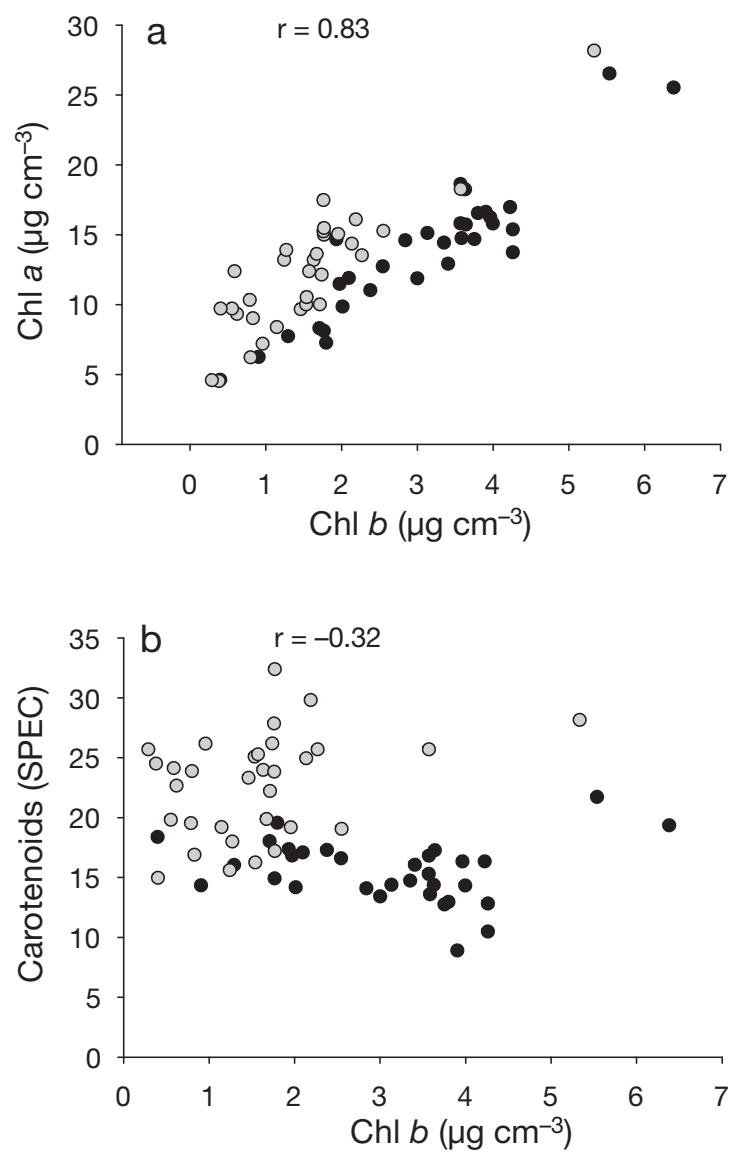

Fig. 3. Means per plot for (a) chl $a$ and $b$ (cryogenic cores; E1), (b) chl $b$ (cryogenic cores) and carotenoids (SPEC; E1), (c) chl $a$ and $b$ (cryogenic cores; E2), (d) chl a (cryogenic cores) and carotenoids (SPEC; E2), (e) carotenoids and chl a and $b$ (SPEC; E2); r values calculated for all data combined; black $=$ KB1, gray $=$ KB2 $(\mathrm{E} 1)$ or TP $(\mathrm{E} 2)$ (see Fig. 1 for details of sites) pigments, many of these analyses showed variation greater than that shown by the Residual for $>1$ spatial scale. In fact, mud in the surface cores showed more variation than the Residual at all scales except $10 \mathrm{~m}$ in E2.

Concentrations of sand showed consistently large components of variation at the scale of shores in deep $(2 \mathrm{~cm})$ and shallow $(3 \mathrm{~mm})$ cores (Table 2), with less sandy sediment on KB1 than on KB2 or TP (shown for E2 in Fig. 4b), although this was not consistent along
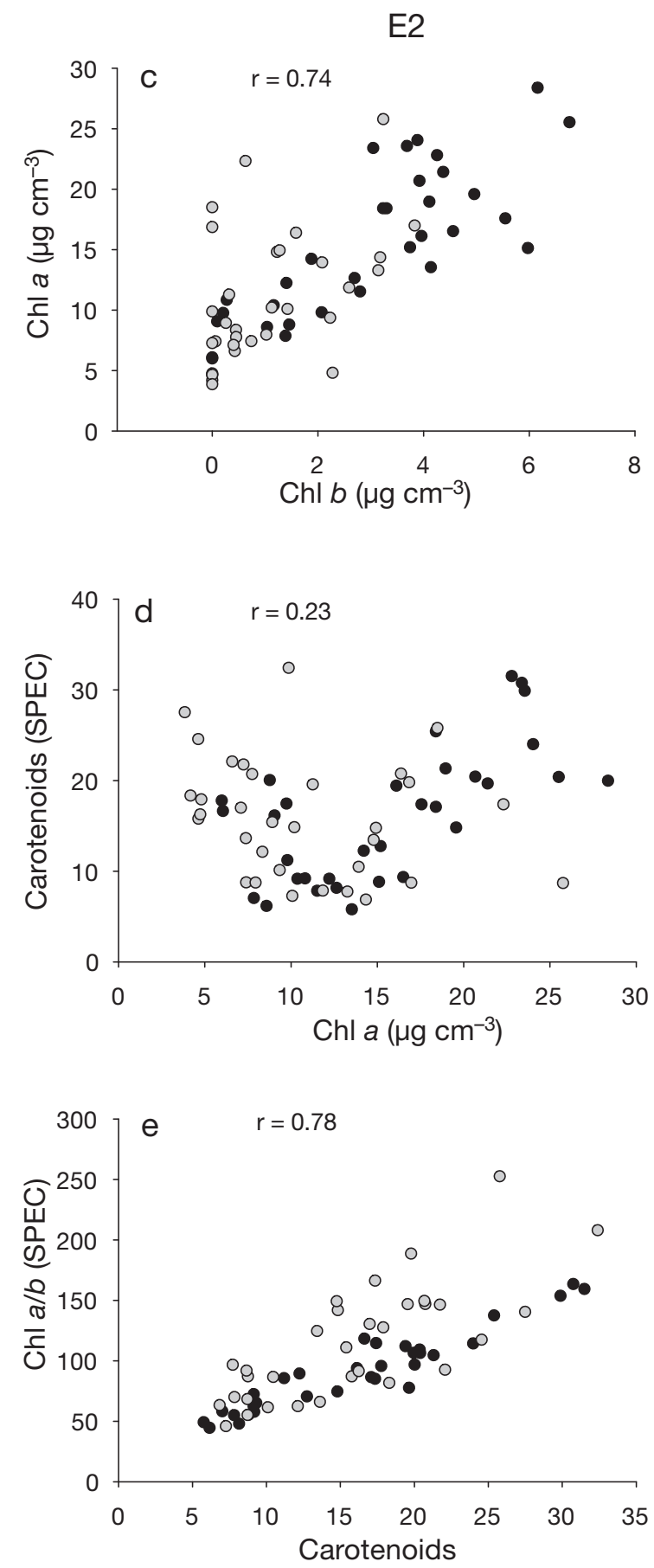


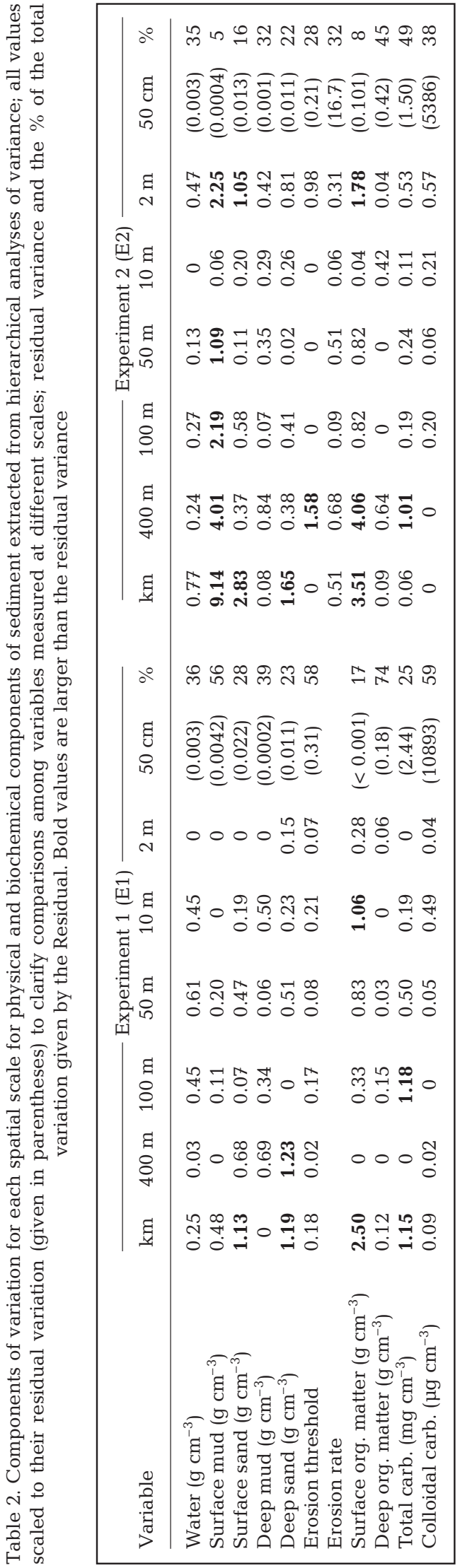

all of the shore. Therefore, as might be expected, the concentrations of sand in shallow and in deep cores were strongly correlated (Fig. 5a). Concentrations of mud, in contrast, did not produce large components of variation for any spatial scales in E1 and only surface mud showed large-scale variation in E2 (Fig. 4c). Shallow and deep mud were less well correlated than was sand (Fig. 5b). The variation at multiple scales for surface mud in E2 was primarily due to the small Residual (compare the average SE between these 2 experiments in Figs. 4c, d), which was one-tenth of the magnitude in E2 (Table 2), although the means were similar between the experiments. In E1, the surface sediment at KB1 contained larger amounts of mud than did KB2; this did not translate into a large between-shore component of variation because of the magnitude of the residual variance.

As for the pigments, there were few large components of variation for 2, 10, 50 or $100 \mathrm{~m}$, except for surface organic matter and total carbohydrate in E1 and for surface mud, sand and organic matter in E2. Surface organic matter and total carbohydrate showed large variation at the scale of shores (E1) and/or $400 \mathrm{~m}$ (E2; Fig. 4e,f), but there were no large-scale patterns in deeper organic matter, nor in colloidal carbohydrate. In E1, there was more organic matter and total carbohydrate on KB1 than on KB2. In E2, organic matter increased between the first and second half of the transect on KB1, but there was little corresponding change in total carbohydrate. On KB2, each variable increased slightly between the first and second half of the transect. Organic matter, surface mud and total carbohydrate were strongly correlated at the scale of plots (Fig. 5c,d), but colloidal carbohydrate was not correlated with other variables and showed no variation larger than that found within plots at any other scale (Table 2).

\section{Benthos}

The benthos was dominated by polychaetes, oligochaetes and nematodes (see also Chapman \& Tolhurst 2004, 2007, Tolhurst \& Chapman 2007). Oligochaetes and nematodes were not identified further because of lack of taxonomic keys, but polychaetes were classified into families, the most abundant and widespread of which were analysed (Table 3). In addition, 3 bivalve species (Soletellina spp., Tellina sp., Mysella trigonella), 1 gastropod genus (Salinator spp.), 2 amphipod species (not formally identified) and copepods (as a group) were abundant enough for analysis, although not always in both experiments. In E1, problems with some samples meant that data were not available for 400 to $562 \mathrm{~m}$ on 
one shore. Therefore, for this experiment, $400 \mathrm{~m}$ was omitted from the analyses (Table 3 ).

Compared to the measures of pigments and sediments, patterns in the benthos were more strongly dominated by small-scale variability. The Residual accounted for $>50 \%$ of the taxa analysed and many of the larger spatial scales contributed zero variance to the total (Table 3). Where there were spatial scales that contributed greater variance than the Residual (e.g. $50 \mathrm{~m}$ for Nereididae and $2 \mathrm{~m}$ for Oligochaeta in E1, Table 3), these were due to occasional large peaks in abundance in scattered plots (Fig. 6a,b). Because of large variation between replicates, the general differences between shores (e.g. differences in abundances of oligochaetes [Fig. 6c] and nereidids on the different shores), did not translate into a large component of variation at that scale. Most taxa were simply very variable at multiple small scales. Many of the taxa were absent from many samples, but these samples differed among taxa and there was no general trend in which plots were occupied along any transect (shown for Tellina sp. in Fig. 6d).

Many taxa (Sabellidae, Owenidae, Spionidae, Capitellidae, Oligochaeta and Nematoda) had much smaller residual variances in E2 than in E1 (Table 3). This could have been due to changes in small-scale patchiness, or because densities were generally smaller in E2, perhaps due to seasonal changes. To examine this, analyses were done separately for KB1, which was sampled each time, incorporating scales from $20 \mathrm{~cm}$ to $400 \mathrm{~m}$. Although most taxa had larger residual variances in E1, when densities were also larger, patterns of variation were similar between the 2 experiments, i.e. most taxa showed most variation at the smallest scale (i.e. $<1 \mathrm{~m}$ between replicates) and many scales added zero variance to the total.

There were no patterns of correlation between any taxa, including those that were taxonomically similar
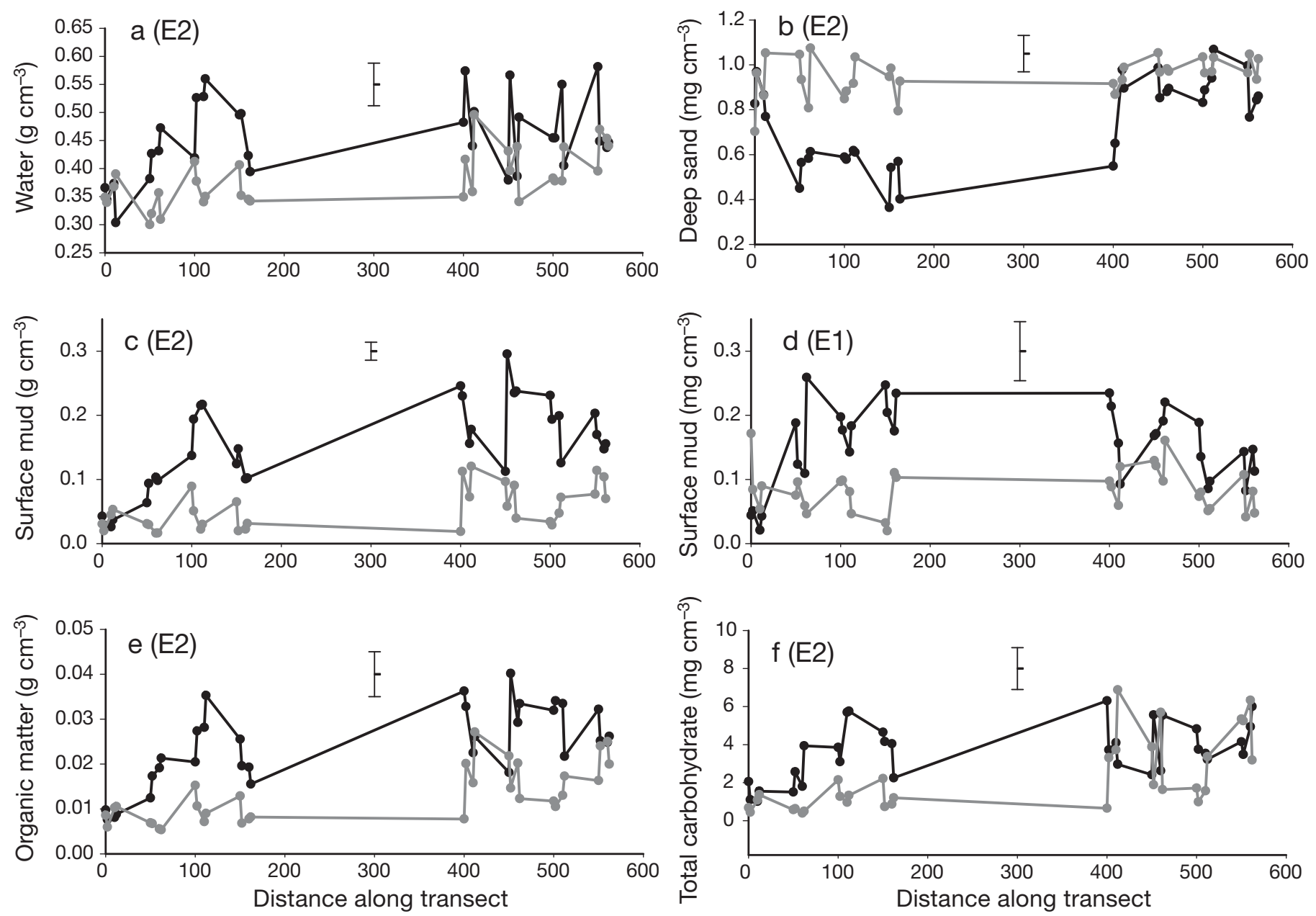

Fig. 4. Means $(\mathrm{n}=2)$ in each of 32 plots along a $562 \mathrm{~m}$ transect on each of 2 shores for concentrations of (a) water (cryogenic cores; E2), (b) sand (deep cores; E2), (c) mud (cryogenic cores; E2), (d) mud (cryogenic cores; E1), (e) organic matter (E2), (f) total carbohydrate (E2); error bar = mean SE for all plots; black = KB1, gray = KB2 (E1) or TP (E2) (see Fig. 1 for details of sites) 
(e.g. between species of amphipods or of bivalves), between taxa that had similar ecological roles (e.g. capitellids and oligochaetes), nor between groups that tend to respond in similar ways to disturbances (e.g. spionids and capitellids).

\section{DISCUSSION}

This study allows a comprehensive comparison of spatial variability in 3 major components of sediments, i.e. photosynthetic pigments, physical and biochemical properties of the sediment and the benthos, at 7 spatial scales ranging from $<1 \mathrm{~m}$ to $>1 \mathrm{~km}$. Each set of measurements was replicated twice.

The benthos, as reported previously for similar assemblages (e.g. Levin 1984, Luckenbach 1986, Schaffner 1990, Morrisey et al. 1992, Thrush et al. 1994, Chapman \& Tolhurst 2007), was extremely variable at the smallest spatial scales measured. Thus, small patches of sediment $(10 \mathrm{~cm}$ across $)$ within a few $\mathrm{cm}$ of each other had very different densities and, for many taxa, these differences were as large as those between cores taken $\mathrm{m}$ to $100 \mathrm{~s} \mathrm{~m}$ or even $\mathrm{km}$ apart. Using larger cores would mask this natural variability, as, indeed, these cores would have masked variability at a scale smaller than $10 \mathrm{~cm}$ (e.g. Joint et al. 1982). This core-size was chosen to obtain counts for a range of taxa that naturally occurred at different densities, without being too dominated by zeroes or singletons, but which were likely to measure variability at the scale of $\sim 50 \mathrm{~cm}$. Generally, on any of the shores sampled, spatial scales between 2 and $400 \mathrm{~m}$ contributed no larger amount of spatial variability than was measured between replicate cores only $50 \mathrm{~cm}$ apart. Densities for most taxa varied more than 5-fold between samples $50 \mathrm{~cm}$ to $50 \mathrm{~m}$ apart. Most spatial scales had smaller variation than found between replicates, leading to zero values for the components of large-scale variation. There were generally no alongshore trends in abun-
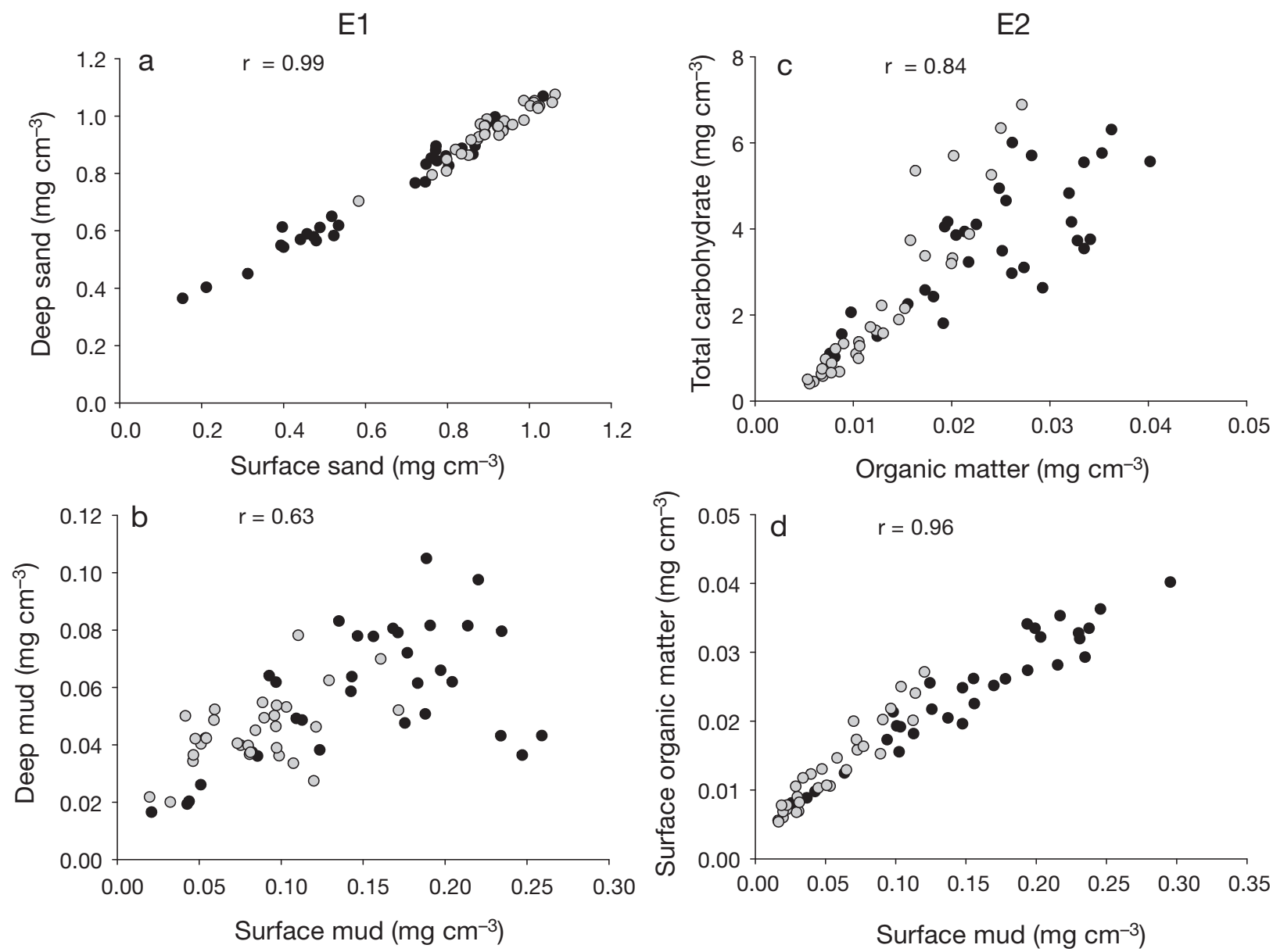

Fig. 5. Mean concentrations per plot of (a) sand in upper (cryogenic cores) and deep sediment (2 cm cores; E1), (b) mud in upper (cryogenic cores) and deep sediment (2 cm cores; E1), (c) organic matter and total carbohydrate (cryogenic cores; E2), (d) mud and organic matter (cryogenic cores; E2); r values calculated for all data combined; black = KB1, gray = KB2 (E1) or TP (E2) (see 


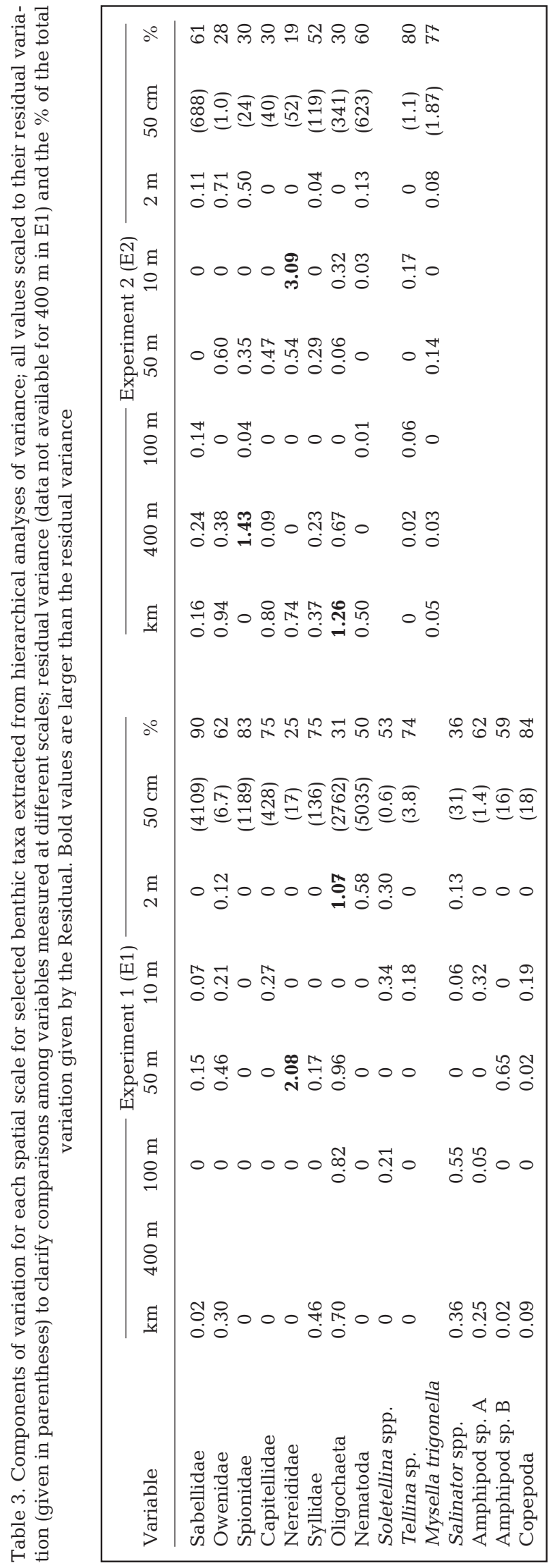

dances over each transect (562 m long), but, where there was a trend (e.g. oligochaetes at KB1 in E2), patterns were still dominated by variation at small scales leading to very large variability around the trend. When intermediate scales had large components of variation, these were often caused by one or a few extremely large values on only one of the shores.

Such large small-scale variation should not simply be ignored. Nor should such data simply be pooled (Magni et al. 2006) in order to make analyses easier. Although it could be caused by stochastic events, it is equally probable or more likely that this variability results from important ecological processes that structure local assemblages at very small scales. For example, recruitment of these fauna appears very unpredictable (Levin 1984), but many fauna recruit in response to variables which vary at scales of $\mathrm{mm}$ to $\mathrm{cm}$ (Krager \& Woodin 1993, Olafsson et al. 1994, Woodin et al. 1995). There is therefore no reason to assume that apparently chaotic patterns shown by many different taxa on different shores are in some way aberrant, or simply uninteresting 'noise' (Carroll 2003), but are probably fine-tuned responses to very variable smallscale variation in sediments (e.g. Levin 1984, Krager \& Woodin 1993, Thrush et al. 1997).

To understand the processes that determine patterns of distribution and abundance and to identify any environmental disturbances that may interrupt them, sampling and experiments must be replicated at appropriate scales in order to (1) provide representative samples of patches of habitat and (2) measure changes in them. Quantifying how much variation there is within a location is mandatory for making inferences about differences between locations. The lack of largescale trends and the fact that densities of all taxa were uncorrelated at any scale provide no guidance about which particular scales should be incorporated into ecological or environmental studies of benthos on these shores. This is unfortunate because infauna and epifauna in soft sediments are considered to be excellent candidates for measuring environmental impacts (Thrush \& Roper 1988, Zajac \& Whitlatch 2003): they are relatively immobile (cf. fish), in close contact with the sediment and the water column, diverse, have many different trophic levels and life-histories and many respond in known ways to contaminants (Bayne et al. 1988). Our results do, however, emphasise the problem of inadequate replication when using such species with very patchy distributions to measure large-scale differences or changes (as discussed by Grant et al. 1997). For all taxa on all shores sampled here, had the samples been either unreplicated, or had only a few replicates from one part of a shore, estimates of densities at the scale of the entire shore would 
E1
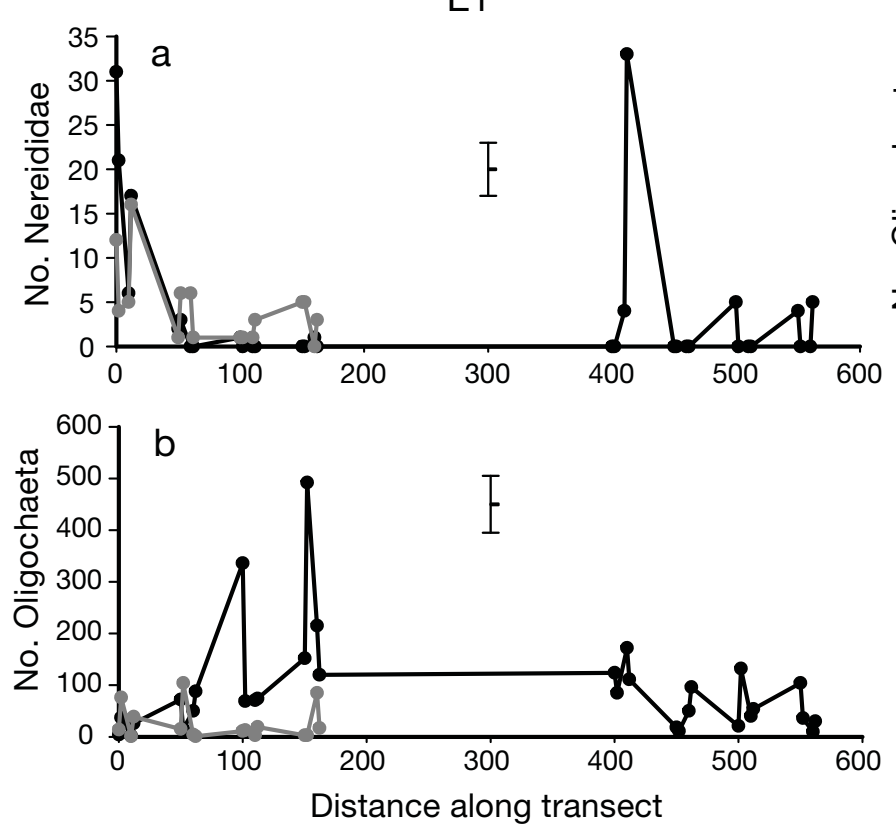

E2
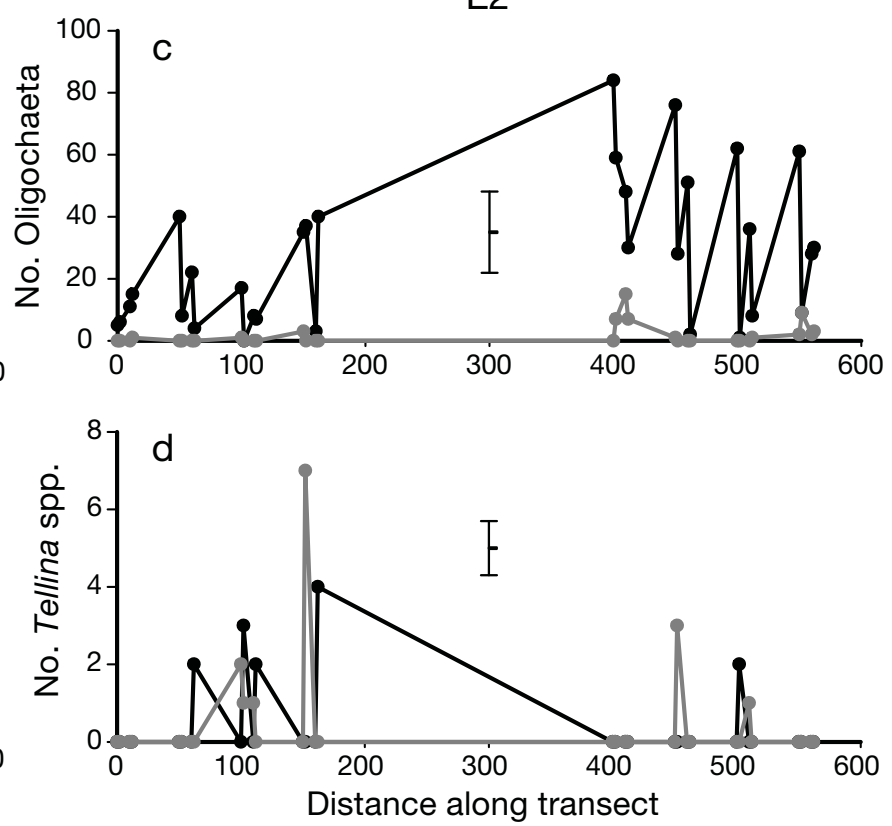

Fig. 6. Means $(\mathrm{n}=2)$ in each of 32 plots along a $562 \mathrm{~m}$ transect on each of 2 shores for numbers of (a) Nereididae (E1), (b) Oligochaeta (E1), (c) Oligochaeta (E2), (d) Tellina spp. (E2); error bar = mean SE for all plots; black = KB1, gray = KB2 (E1) or TP (E2) (see Fig. 1 for details of sites)

have been extremely over- or underestimated and spurious differences would have been found between shores. They also show that different taxa had very different patterns, even at small spatial scales and for taxa that one would predict should respond to similar environmental factors. Thus, small-scale environmental variation is likely to be more important in structuring many benthic assemblages than large-scale processes, such as wave action, with different components of the assemblage responding differently to a range of environmental variables that are themselves poorly correlated at a range of spatial scales. Understanding these relationships requires that considerable thought goes into measuring patterns of biotic and abiotic variables.

The other biotic component of sediments measured here was the photosynthetic pigments, as a surrogate for micro-algal biomass and composition (Millie et al. 1993, Honeywill et al. 2002). These showed more large-scale variation than did the benthos, with large components of variation for some pigments at the scale of shores or $400 \mathrm{~m}$ in each experiment. Nevertheless, quite different patterns were obtained from the different measures, some of which were easily interpretable, although others were not. For example, in E1, there were more carotenoids (possibly due to diatoms) on KB2 and chl $b$ (possibly due to green algae) on KB1. The large component of variation associated with shores in the SPEC measure of chl $a$ and $b$ was almost certainly caused by chl $b$ because the extracted (core) chl a did not show the same pattern. E2 was more difficult to interpret because, although core chl $a$ and $b$ showed significant variation at $400 \mathrm{~m}$ on KB1 creating large variation at this scale, SPEC measures of chl a and $b$ showed no similar variation. The changes in core chllorophyll did, however, match changes in SPEC measures of carotenoids, suggesting that they may have been due to diatoms.

Apart from these 2 examples, all other measures of photosynthetic pigments were, as for most of the benthos, dominated by small-scale variation, with variation at larger scales no bigger than between cores $<1 \mathrm{~m}$ apart. This should not be surprising; fauna and microflora might be expected to vary at similar scales because (1) the algae may be a resource for the animals, (2) activity of fauna (e.g. production of faeces) can locally increase micro-algae (Connor et al. 1982) and (3) similar small-scale disturbances or microtopography of the substratum may influence both fauna and flora. Many studies of microflora in sediments have, however, not been well replicated, in part due to the time-consuming methods of estimating micro-algae biochemically. For example, a single plot has been used to represent a height on a shore (Underwood \& Paterson 1993) or a location (Sun et al. 1994), which could lead to apparent, but spurious, differences among heights or locations, simply because the few samples were in a patch of small values at one height 
(or shore) and in a patch of large values in another. Recent techniques of measuring micro-algae in situ using remote methods (e.g. Murphy et al. 2004, 2005) have unambiguously demonstrated that micro-algae are distributed with extremely variable small-scale patchiness; indeed, with large amounts of variation at scales much smaller than those measured here.

Chl $a$ and $b$ from the cryogenic cores were generally positively correlated along a transect, as might be expected as the measures were extracted from the same small cores. There was, however, little correlation between these measures and indirect estimates of chlorophyll from the SPEC. This was probably due to the fact that the cores and SPEC measures were not from the same small patches, so the correlation was at the scale of the plot $\left(0.25 \mathrm{~m}^{2}\right)$, with the values for each plot obtained from the mean estimated from the 2 replicate cores or SPEC measures per plot. Thus, the different scales at which algae varied along each of these transects depended on the method of measurement and/or the specific places within each plot that each measurement was made. This emphasizes not only the need for adequate replication at multiple spatial scales to quantify larger-scale trends, but also consideration of the methods being used to estimate micro-algae when different methods reveal different ecological patterns (Grinham et al. 2007).

The concentrations of sand and of mud were measured in the surface $3 \mathrm{~mm}$ and in sediment to $2 \mathrm{~cm}$ depth. Although one might expect good correlations between these measures, this was only consistently true for concentrations of sand, which were very tightly correlated between shallow and deep cores in each experiment. Thus, large differences in relative amounts of sand between KB1 and the other shores produced large components of variation at the scale of shores. Concentrations of mud at the different depths were less tightly correlated with each other or with concentrations of sand, possibly because the concentration of mud is strongly affected by the amount of water in the sediment. Alternatively, mud may vary more with depth than does sand, or the microphytobenthos lying on the surface may retain mud locally, increasing small-scale variability. Thus, patterns of variation in mud were more variable within and between experiments. The different spatial scales at which fauna, micro-algae and sedimentary properties varied is quite surprising considering the perceived strong associations between sediment, fauna (Gray 1974) and micro-algae (Davis \& McIntyre 1983, Cahoon et al. 1999).

Although there was some correlation between patterns in amounts of surface organic matter, mud and total carbohydrate, colloidal carbohydrates showed different patterns of variation and were poorly correlated with all other measures. Large amounts of small- scale variability in many different sedimentary properties, biomass and composition of microflora and benthos may explain why the rate or threshold of erosion did not show any large-scale patterns. Erosion is influenced by many abiotic and biotic properties of sediments, but when these themselves show different spatial patterns which are largely uncorrelated, patterns of erosion are difficult to predict and the factors determining the stability of sediments are likely to vary from place to place at small spatial scales. This supports Defew et al. (2002) who stated that the importance of the various factors that determine sediment-stability are site-specific.

These results showing the large amount of smallscale variation in all biotic and abiotic properties indicate that the processes that influence them will also differ at similar spatial scales. Thus, in terms of the original hypotheses, there was no indication that either were supported. In particular,(1) functionally similar biota showed different and uncorrelated patterns of abundances at all scales; (2) except for some measures of photosynthetic pigments, physical, biochemical and biotic (both microflora and macrofauna) measures showed variable patterns of spatial variability and were largely uncorrelated; (3) many large-scale differences in these variables were due to isolated peaks of concentrations in haphazard plots along one of the 2 shores being compared.lids).

\section{CONCLUSIONS}

So, when sampling to estimate magnitudes of individual variables, sampling only one or few replicates in an area, or one small patch to represent an extensive habitat (e.g. Sun et al. 1994, Thrush et al. 1996, Haubois et al. 2005), are extremely unlikely to be representative unless the sediments are homogeneous over larger spatial scales. These analyses have shown that all components of sediments vary at small scales of $<1 \mathrm{~m}$. Yet many studies have sampled very few or only 1 replicate to represent a site, or have pooled samples, thus losing information about small-scale variability. If this small-scale variability is not incorporated into sampling schemes, or samples are pooled within a site, one cannot distinguish whether a difference found between 2 sites is due to a single extremely large or small value from one set of replicates, or due to a difference between the sites that exists, on average, across all replicates. The extent to which sampling does represent the area being considered in the hypothesis needs to be demonstrated, not assumed. This is crucial when comparing different areas or different times of sampling an area, otherwise unrepresentative sampling can create spurious patterns of 
spatial or temporal differences (as discussed by Thrush et al. 1994, Grant et al. 1997). This is particularly important when assessing environmental impacts or restoration because spurious results based on inadequate representation of a potentially impacted, reference and/or control sites could have extremely serious ecological consequences or lead to expensive, but wasteful, management.

Second, correlations between different sediment components and biota need to incorporate the multiple spatial scales at which there may be variation. Otherwise, large-scale correlation (e.g. between bays) may appear to be important, simply because small-scale correlation (within bays) has not been measured. Yet, if within-bay variation is as large as, or larger than that found between bays, then the scale of the process(es) that cause such variation need to be reconsidered. In this study, all variables were extremely patchy along each shore, with occasional extremely large values. The positions of these 'high spots' were not the same for the benthos and sedimentary variables. Very large, although haphazardly situated, values of a variable will contribute to large differences between places at larger scales, i.e. a particularly large value in one point will increase the mean value of that over a much larger scale than at that one point (see also Grant et al. 1997).

Third, although it is never possible to exclude stochastic events that might cause this small-scale, socalled 'noise', it is unreasonable to assume that it is the dominant cause of small-scale variation everywhere and at all times (Carroll 2003). Whenever variation in sediments and the biota has been measured at multiple scales, it is shown to be very large at scales of $\mathrm{cm}$ to only a few m (e.g. Levin 1984, Decho \& Fleeger 1988, Pinckney \& Sandulli 1990, Morrisey et al. 1992, Tolhurst \& Chapman 2007). For many biota, this is the scale at which they move, feed, excrete, etc. and therefore this is the scale at which interactions occur between species and between biota and their environment. Thus, even when large components of the biota themselves can create new sedimentary habitats, variation of other biota within and between such habitats are mainly found at small spatial scales within habitats (Krager \& Woodin 1993, Thrush et al. 1996, Tolhurst \& Chapman 2007).

Ecological relationships between microflora, macrofauna and sedimentary properties can be first examined by testing for relationships between biotic and abiotic variables. Significant positive or negative correlations will allow one to develop clear hypotheses about which components of sediment the fauna may be responding to, although unambiguous tests of ecological relationships requite experimental manipulations, rather than correlations of patterns (Underwood et al. 2000). The data in this study show that to obtain good estimates of such relationships, data need to be collected over multiple spatial scales because different properties of sediment and different taxa varied at different scales. This study does, however, provide a large data-set for such tests, which will provide a strong evaluation about how general such relationships are in these sediments.

It has been asserted that many experimental manipulations are potentially too small to measure ecological processes within the relevant environment of many species and that edge-effects among other artifacts may dominate results in manipulated plots (Thrush et al. 1996). This is indeed true, but manipulating large areas of sediment to overcome such problems, then sampling such experiments with minimal or no replication, cannot solve this problem. It is clear that to understand animal-animal, sediment-sediment and animal-sediment interactions, it is necessary to do experimental manipulations that are not only replicated over large scales, but also at multiple nested scales within these and to incorporate appropriate replicate measures at each scale. Only then will it be possible to start to understand the diverse direct and indirect inter-relationships between biotic and abiotic components of this complex habitat.

Acknowledgements. Numerous members of the skilled and competent Research Support Staff in the Centre for Research on Ecological Impacts of Coastal Cities assisted with all aspects of this study and the preparation of this manuscript. This research was supported by the Australian Research Council through its Special Research Centre Scheme and Discovery Research Grants and by the University of Sydney. Two reviewers offered helpful comments on an earlier draft of this manuscript.

\section{LITERATURE CITED}

Andersen TJ (2001) Seasonal variation in erodibility of two temperate, microtidal mudflats. Estuar Coast Shelf Sci 53: $1-12$

> Azovsky AI (2002) Size-dependent species-area relationships in benthos: Is the world more diverse for microbes? Ecography 25:273-282

Bayne BL, Clarke KR, Gray JS (eds) (1988) Biological effects of pollutants. Mar Ecol Prog Ser 46:1-278

Bidigare RR, Morrow JH, Kiefer DA (1989) Derivative analysis of spectral absorptions by photosynthetic pigments in the western Sargasso Sea. J Mar Res 47:323-341

Blanchard GF, Paterson DM, Stal LJ, Richard P and others (2000) The effect of geomorphological structures on potential biostabilisation by microphytobenthos on intertidal mudflats. Cont Shelf Res 20:1243-1256

Branch GM, Pringle A (1987) The impact of the sand prawn Callianassa kraussi stebbing on sediment turnover and on bacteria, meiofauna, and benthic microflora. J Exp Mar Biol Ecol 107:219-235

> Cahoon LB, Nearhoof JE, Tilton CL (1999) Sediment grain size effect on benthic macroalgal biomass in shallow aquatic ecosystems. Estuaries 22:735-741

Carroll RJ (2003) Variances are not always nuisance parame- 
ters. Biometrics 59:211-220

Chapman MG, Tolhurst TJ (2004) The relationship between invertebrate assemblages and bio-dependant properties of sediment in urbanized temperate mangrove forests. J Exp Mar Biol Ecol 304:51-73

Chapman MG, Tolhurst TJ (2007) Relationships between benthic macrofauna and biogeochemical properties of sediments at different spatial scales and among different habitats in mangrove forests. J Exp Mar Biol Ecol 343:96-109

Commito JA, Currier CA, Kane LR, Reinsel KA, Ulm IM (1995) Dispersal dynamics of the bivalve Gemma gemma in a patchy environment. Ecol Monogr 65:1-20

Connor MS, Teal JM, Valiela I (1982) The effect of feeding by mud snails, Ilyanassa obsoleta (Say.), on the structure and metabolism of a laboratory benthic algal community. J Exp Mar Biol Ecol 65:29-45

Cummings VJ, Thrush SF, Hewitt JE, Turner SJ (1998) The influence of the pinnid bivalve Atrina zelandica (Gray) on benthic macroinvertebrate communities in soft-sediment habitats. J Exp Mar Biol Ecol 228:227-240

> Davis MW, McIntyre CD (1983) Effects of physical gradients on the production dynamics of sediment-associated algae. Mar Ecol Prog Ser 13:103-114

$>$ Decho AW, Fleeger AW (1988) Microscale dispersion of meiobenthic copepods in response to food-resource patchiness. J Exp Mar Biol Ecol 118:229-243

> Defeo O, McLachlan A (2005) Patterns, processes and regulatory mechanisms in sandy beach macrofauna: a multiscale analysis. Mar Ecol Prog Ser 295:1-20

Defew EC, Paterson DM, Hagerthey SE (2002) Site-specific features influence sediment stability of intertidal flats. Hydrol Earth Syst Sci 6:971-981

> Dethier MN, Schoch GC (2006) Taxonomic sufficiency in distinguishing natural spatial patterns on an estuarine shoreline. Mar Ecol Prog Ser 306:41-49

Fletcher DJ, Underwood AJ (2002) How to cope with negative estimates of components of variance in ecological field studies. J Exp Mar Biol Ecol 273:89-95

> Forbes VE, Lopez GR (1989) The role of sediment particle size in the nutritional energetics of a surface deposit-feeder. I. Ingestion and absorption of sedimentary microalgae by Hydrobia truncata (Vanatta). J Exp Mar Biol Ecol 126: 181-192

Grant J, Turner SJ, Legendre P, Hume TM, Bell RG (1997) Patterns of sediment reworking and transport over small spatial scales on an intertidal sandflat, Manukau Harbour, New Zealand. J Exp Mar Biol Ecol 216:33-50

Gray JS (1974) Animal-sediment relationships. Oceanogr Mar Biol Annu Rev 12:223-261

Grinham AR, Carruthers TJB, Fisher PL, Udy JW, Dennison WC (2007) Accurately measuring the abundance of benthic microalgae in spatially variable habitats. Limnol Oceanogr Methods 5:119-125

Guarini JM, Blanchard GF, Bacher C, Gros P and others (1998) Dynamics of spatial patterns of microphytobenthic biomass: inferences from a geostatistical analysis of two comprehensive surveys in Marennes-Oleron Bay (France). Mar Ecol Prog Ser 166:131-141

Hansen K, Kristensen E (1997) Impact of macrofaunal recolonization on benthic metabolism and nutrient fluxes in a shallow marine sediment previously overgrown with macroalgal mats. Estuar Coast Shelf Sci 45:613-628

Haubois AG, Sylvestre F, Guarini JM, Richard P, Blanchard GF (2005) Spatio-temporal structure of the epipelic diatom assemblage from an intertidal mudflat in MarennesOleron Bay, France. Estuar Coast Shelf Sci 64:385-394

Honeywill C, Paterson DM, Hagerthy SE (2002) Determination of microphytobenthic biomass using pulse-amplitude modulated minimum fluorescence. Eur J Phycol 37: 485-492

Huettel M, Gust G (1992) Impact of bioroughness on interfacial solute exchange in permeable sediments. Mar Ecol Prog Ser 89:253-267

> Joint IR, Gee JM, Warwick RM (1982) Determination of finescale vertical distribution of microbes and meiofauna in an intertidal sediment. Mar Biol 72:157-164

Kelaher BP, Levinton JS (2003) Variation in detrital enrichment causes spatio-temporal variation in soft-sediment assemblages. Mar Ecol Prog Ser 261:85-97

> Kendall MA, Widdicombe S (1999) Small scale patterns in the structure of macrofaunal assemblages of shallow soft sediments. J Exp Mar Biol Ecol 237:127-140

Krager CD, Woodin SA (1993) Spatial persistence and sediment disturbance of an arenicolid polychaete. Limnol Oceanogr 38:509-520

> Levin LA (1984) Life history and dispersal patterns in a dense infaunal polychaete assemblage: community structure and response to disturbance. Ecology 65:1185-1200

> Levin SA (1992) The problem of pattern and scale in ecology. Ecology 73:1943-1967

Luckenbach MW (1986) Sediment stability around animal tubes: the roles of hydrodynamic processes and biotic activity. Limnol Oceanogr 31:779-787

Magni P, Como S, Montani S, Tsutsumi H (2006) Interlinked temporal changes in environmental conditions, chemical characteristics of sediments and macrofaunal assemblages in an estuarine intertidal sandflat (Seto Inland Sea, Japan). Mar Biol 149:1185-1197

Migne A, Spilmont N, Davoult D (2004) In situ measurements of benthic primary production during emersion: seasonal variations and annual production in the Bay of Somme (eastern English Channel, France). Cont Shelf Res 24: 1437-1449

> Millie DF, Paerl HW, Hurley JP (1993) Microalgal pigment assessments using high-performance liquid chromatography: a synopsis of organismal and ecological applications. Can J Fish Aquat Sci 50:2513-2527

Morrisey DJ, Howitt L, Underwood AJ, Stark JS (1992) Spatial variation in soft-sediment benthos. Mar Ecol Prog Ser 81: 197-204

> Murphy RJ, Tolhurst TJ, Chapman MG, Underwood AJ (2004) Estimation of surface chlorophyll on an exposed mudflat using digital colour-infrared (CIR) photography. Estuar Coast Shelf Sci 59:625-638

> Murphy RJ, Tolhurst TJ, Chapman MG, Underwood AJ (2005) Estimation of surface chlorophyll a on an exposed mudflat using field spectrometry: accuracy of ratios and derivative-based approaches. Int J Remote Sens 26: 1835-1859

- Murphy RJ, Chapman MG, Tolhurst TJ, Underwood AJ (2008) Spatial variation of chlorophyll on estuarine mudflats determined by field-based remote sensing. Mar Ecol Prog Ser 365:45-55

Olafsson EB, Peterson CH, Ambrose WGJ (1994) Does recruitment limitation structure populations and communities of macro-invertebrates in marine soft sediments: the relative significance of pre- and post-settlement processes. Oceanogr Mar Biol Annu Rev 32:65-109

> Olsgard F, Brattegard T, Holthe T (2003) Polychaetes as surrogates for marine biodiversity: lower taxonomic resolution and indicator groups. Biodivers Conserv 12:1033-1049

Palmer MW (1988) Fractal geometry: a tool for describing spatial patterns of plant communities. Vegetatio 75:91-102

> Pinckney J, Sandulli R (1990) Spatial autocorrelation analysis of meiofaunal and microalgal populations on an intertidal 
sandflat: scale linkage between consumers and resources. Estuar Coast Shelf Sci 30:341-353

Saburova MA, Polikarpov IG, Burkovsky IV (1995) Spatial structure of an intertidal microphytobenthic community as related to different spatial scales. Mar Ecol Prog Ser 129: 229-239

Savitzky A, Golay MJE (1964) Smoothing and differentiation of data by simplified least squares procedures. Anal Chem 36:1627-1639

Schaffner LC (1990) Small-scale organism distributions and patterns of species diversity: evidence for positive interactions in an estuarine benthic community. Mar Ecol Prog Ser 61:107-117

Sun MY, Aller RC, Lee C (1994) Spatial and temporal distributions of sedimentary chloropigments as indicators of benthic processes in Long Island Sound. J Mar Res 52: 149-176

Thrush SF, Roper DS (1988) Merits of macrofaunal colonization of intertidal mudflats for pollution monitoring: preliminary study. J Exp Mar Biol Ecol 116:219-235

Thrush SF, Pridmore RD, Hewitt JE (1994) Impacts on softsediment macrofauna: the effects of spatial variation on temporal trends. Ecol Appl 4:31-41

Thrush SF, Whitlatch RB, Pridmore RD, Hewitt JE, Cummings VJ, Wilkinson MR (1996) Scale-dependent recolonization: the role of sediment stability in a dynamic sandflat habitat. Ecology 77:2472-2487

Thrush SF, Cummings VJ, Dayton PK, Ford R and others (1997) Matching the outcome of small-scale density manipulation experiments with larger scale patterns an example of bivalve adult/juvenile interactions. J Exp Mar Biol Ecol 216:153-169

Thrush SF, Hewitt JE, Gibbs M, Lundquist C, Norkko A (2006) Functional role of large organisms in intertidal communities: community effects and ecosystem function. Ecosystems (NY, Print) 9:1029-1040

Tolhurst TJ, Chapman MG (2007) Patterns in biogeochemical properties of sediments and benthic animals among different habitats in mangrove forests. Austral Ecol 32:775-788

Tolhurst TJ, Black KS, Shayler SA, Mather S, Black I, Baker K,

Editorial responsibility: Romuald Lipcius,

Gloucester Point, Virginia, USA
Paterson DM (1999) Measuring the in situ erosion shear stress of intertidal sediments with the Cohesive Strength Meter (CSM). Estuar Coast Shelf Sci 49:281-294

> Tolhurst TJ, Underwood AJ, Perkins RG, Chapman MG (2005) Content versus concentration: effects of units on measuring the biogeochemical properties of sift sediments. Estuar Coast Shelf Sci 63:665-673

Underwood AJ (1981) Techniques of analysis of variance in experimental marine biology and ecology. Oceanogr Mar Biol Annu Rev 19:513-603

> Underwood AJ, Chapman MG (1996) Scales of spatial patterns of distribution of intertidal invertebrates. Oecologia 107:212-224

> Underwood AJ, Chapman MG, Connell SD (2000) Observations in ecology: You can't make progress on processes without understanding the patterns. J Exp Mar Biol Ecol 250:97-115

Underwood GJC, Paterson DM (1993) Recovery of intertidal benthic diatoms after biocide treatment and associated sediment dynamics. J Mar Biol Assoc UK 73:25-45

Van Blaricom GR (1982) Experimental analyses of structural regulation in a marine sand community exposed to oceanic swell. Ecol Monogr 52:283-305

Whitlatch RB (1981) Animal-sediment relationships in intertidal marine benthic habitats: some determinants of deposit-feeding species diversity. J Exp Mar Biol Ecol 53: $31-46$

Whitlatch RB, Lohrer AM, Thrush SF, Pridmore RD, Hewitt JE, Cummings VJ, Zajac RN (1998) Scale-dependent benthic recolonization dynamics: life stage-based dispersal and demographic consequences. Hydrobiologia 375/376: $217-226$

Wiens JA (1989) Spatial scaling in ecology. Funct Ecol 3:385-397

Woodin SA, Lindsay SM, Wethey DS (1995) Process-specific recruitment cues in marine sedimentary systems. Biol Bull 189:49-58

Zajac RN, Whitlatch RB (2003) Community and populationlevel responses to disturbance in a sandflat community. J Exp Mar Biol Ecol 294:101-125

Submitted: May 22, 2009; Accepted: September 17, 2009 Proofs received from author(s): December 14, 2009 